\title{
Properties of waste of chemical processing of germanium concentrates
}

\author{
(C) Igor N. Tanutrov, ${ }^{*}$ and Marina N. Sviridova ${ }^{+}$ \\ Institute of Metallurgy of Ural Branch of Russian Academy of Sciences. \\ Amundsen St., 101. Ekaterinburg, 620016. Sverdlovsk Region. Russia. \\ Phone:+7 (904) 380-56-57. E-mail: intan38@live.ru
}

\begin{abstract}
*Supervising author; ${ }^{+}$Corresponding author
Keywords: waste, germanium concentrate, chemical processing, waste, physical and chemical properties.
\end{abstract}

\section{Abstract}

In order to increase the through extraction of germanium in the technology of production of germanium concentrates, as well as finding ways to eliminate the accumulation of toxic waste, using modern techniques and equipment, the physical and chemical properties of waste chemical processing of germanium concentrates (OHGC) of two domestic enterprises were experimentally studied.

The main components of OHGC are: sulphate hemihydrate $\mathrm{CaSO}_{4} \cdot 0.5 \mathrm{H}_{2} \mathrm{O}$ and hypochlorite $\mathrm{Ca}(\mathrm{OCl})_{2}$ calcium. The moisture content of the sludge amounted to $30-50 \%$. The content of germanium in the cakes of both companies is in the range of 0.20 and $0.27 \%$, respectively, indicating the feasibility of recovery in the Ge. At the same time, the samples of cakes differ significantly in the content of impurities, which depends on the types of raw materials in the preparation of concentrates.

Granulometric composition of cakes is characterized by high dispersion. With an average diameter of $12 \mu \mathrm{m}$, all particle sizes are in the range of $0.5-15 \mu \mathrm{m}$. The distribution of particle sizes is shifted in interval of $0-15 \mu \mathrm{m}$, and the area of the particles less than $3 \mu \mathrm{m}$ is not more than $10 \%$. The high dispersion of the cake is reflected in the specific surface area, which is $23.7 \mathrm{~m}^{2} / \mathrm{g}$.

Thermographic study found that the heating of the sample cake is accompanied by two endothermic effects of dehydration at 110 and $145-168{ }^{\circ} \mathrm{C}$ calcium sulfate and hypochloride semihydrate with correspondding weight loss of 13.1 and $12.9 \%$.

The presence of toxic impurities (arsenic, zinc and lead), as well as chlorine, presents significant challenges for the development of disposal technology with the extraction of germanium. Assuming that the undiscovered part of the germanium in the concentrate is compounds or solid solutions with silicon dioxide, an effective technology should include their reagent high temperature treatment.

\section{References}

[1] I.N. Tanutrov, M.N. Sviridova. Scientific substantiation, development and implementation of pyrometallurgical technology for production of germanium concentrates. Nonferrous Metals. 2014. No.2(854). P.71-75. (russian)

[2] Concentrate of germanium. TU 1774-003-95961127-2008.

[3] V.M. Andreev, A.S. Kuznetsov, G.I. Petrov, L.N. Shigina. Production Germany. Moscow: Metallurgy. 1969. 93p. (russian)

[4] M.Ya. Shpirt. Physical, chemical and technological principles of production of compounds of Germany. Apatity: Publ. Kolar scientific center, RAS. 2006. 286p. (russian)

[5] O.V. Nechvoglod, and A.G. Upolovnikova. The study of the phase composition of the products of electrochemical oxidation of sulfide granules of the system $\mathrm{Cu}_{1.96} \mathrm{~S}_{-}-\mathrm{Ni}_{3} \mathrm{~S}_{2}-\mathrm{Cu}-\mathrm{Ni}$. Butlerov Communications. 2019. Vol.57. No.3. P.149-154. DOI: 10.37952/ROI-jbc-01/19-57-3-149

[6] S.N. Golovin, M.N. Yaprintsev, I.G. Ryltsova, and O.E. Lebedeva. Influence of nature of the precipitating agent and chemical-thermal treatment on the phase composition of cerium-containing layered double hydroxides. Butlerov Communications. 2018. Vol.56. No.12. P.126-130. DOI: 10.37952/ROI-jbc-01/1856-12-126

[7] A.N. Popova, Ch.N. Barnakov, G.P. Khohlova. The study of the structural characteristics of carbon Materials by mean of XRD analysis. Butlerov Communications. 2018. Vol.56. No.11. P.153-159. DOI: 10.37952/ROI-jbc-01/18-56-11-153

[8] A.N. Gabdullin, E.A. Nikonenko, T.M. Klyuev, and V.F. Markov. Chemical and phase composition of oxidized nickel ores of the Kulikovsky deposit - raw materials for the production of magnesium 

compounds, Fe-Ni-containing concentrates, $\mathrm{SiO}_{2}$. Butlerov Communications. 2018. Vol.55. No.8. P.156161. DOI: $10.37952 /$ ROI-jbc-01/18-55-8-156

[9] A.E. Buntin, R.O. Sirotkin, and O.S. Sirotkin. Features of chemical structure, properties and technology of inorganic products based on oxides. Butlerov Communications. 2018. Vol.53. No.2. P.153-160. DOI: 10.37952/ROI-jbc-01/18-53-2-153

[10] Michael E. Barsan et al. NIOSH Pocket Guide to Chemical Hazards. DHHS (NIOSH) Publication No. 2005-149. National Institute for Occupational Safety and Health. 2007. 454p.

[11] N.Ah. Andreeva. Chemistry of cement and binders. St. Petersburg.: SPSUACE. 2011. 67p. (russian) 